\title{
VEJEZ Y TRANSFORMACIONES
}

\section{Dispositivo grupal de mediación artística en prácticas de intervención en la vejez}

\author{
Soledad Acevedo Barcia ${ }^{1}$
}

\section{Introducción}

El presente trabajo parte fundamentalmente de la reflexión sobre mi vínculo personal con la vejez y la mirada sobre ésta, del gusto (y disgustos momentáneos) por la psicología, el arte, la filosofía; del tránsito y el devenir profesional-personal.

Desde el año 2015, junto a una colega llevamos adelante un proyecto autogestionado de diagramación y coordinación de espacios grupales en Asociaciones de Jubilados y Pensionistas pertenecientes a ONAJPU (Organización Nacional de Asociaciones de Jubilados y Pensionistas del Uruguay). En un comienzo el espacio apuntó a la estimulación cognitiva como modo de potenciar la autonomía. En aquel momento los objetivos estuvieron orientados a la prevención del deterioro mental, porque entendíamos que la calidad de vida del sujeto, estaba estrechamente relacionada con un adecuado funcionamiento cognitivo. Partiendo desde un modelo de envejecimiento que toma a la vejez como pérdida de autonomía, nosotros como profesionales, atenderíamos y asistiríamos a sus demandas, y también las construiríamos.

Impregnadas por una determinada lógica, que piensa a la vejez desde un modelo organicista, nos iniciamos en un camino de múltiples desafíos y sorpresas. La pertenencia y empoderamiento grupal generó que se comenzase a cuestionar nuestra práctica, lo que si bien, era uno de los objetivos perseguidos, al objetivarse, resultó una gran movilización profesional de crisis y aprendizaje. La grupalidad comenzó a elaborar sus propias demandas, y a diseñar formas posibles desde las cuales encontrar una respuesta singular. En este contexto, comenzamos a transitar un camino tendiente a entender al sujeto desde un diálogo constante con el entramado que lo va produciendo y del cual es productor.

A partir del análisis de las prácticas y la interrogación sobre la concepción de sujeto desde la cual intervenimos, devenimos en un espacio que actualmente apunta a la reflexión 
grupal sobre el proceso de envejecimiento y la posibilidad de generar un posicionamiento crítico en relación al mismo.

En este marco se realizó la intervención que desarrollé durante el año 2017, en la Diplomatura de Psicogerontología de la UdelaR. La selección de la institución tomada para ello, se efectuó en base a que la misma resultase un desafío a nivel de la intervención. Es así cómo se intervino en una asociación donde se observó a nivel institucional y grupal, rigideces en la comunicación entre sus miembros y con el resto de la comunidad, constituyéndose la misma como una institución con aspectos conservadores.

Es importante destacar que históricamente la institución se conforma desde la división de un sector de jubilados de un mismo rubro, a partir de diferencias ideológicas, constituyéndose la misma a partir del sector alineado ideológicamente a posturas conservadoras2.

A nivel grupal, se observó en sus integrantes, una concepción sobre la vejez, arraigada a un "modelo tradicional de envejecimiento" (Berriel, Paredes \& Pérez, 2006), desde la desvalorización y el prejuicio, mediante la asociación de la vejez y el envejecimiento a la enfermedad, discapacidad, deterioro y dependencia. Se partió de la hipótesis de que el conservadurismo institucional influiría en la concepción conservadora grupal sobre la vejez.

Junto a la colega con la cual trabajé, nos propusimos el objetivo de habilitar un espacio de reflexión grupal, el cual propiciara la construcción de narrativas identitarias alternativas (Villar, 2015) del propio proceso de envejecimiento, a partir de la utilización de mediadores artísticos.

Desde el análisis del proceso de intervención, se observó que si bien el grupo adquirió ciertos posicionamientos críticos, en torno a representaciones hegemónicas sobre la vejez, se generó una dialéctica constante de apertura reflexiva, seguida por la reaparición de elementos conservadores, sin embargo, en función a las características del grupo, los cambios de posicionamiento subjetivo se consideraron importantes. En este sentido, las líneas de acción a seguir que nos planteamos con dicho grupo fueron: continuar con el

2 Más adelante en la discusión retomaré este punto, mediante viñetas que ilustran posturas apegadas al mantenimiento de valores políticos, sociales y morales tradicionales. 
trabajo a partir de la metodología grupal, posibilitadora de movilizaciones subjetivas, en conjunción con el aporte de los mediadores artísticos, cuyo entrecruzamiento, demostró la apertura hacia un posicionamiento crítico sobre representaciones subjetivas cristalizadas entorno al proceso de envejecimiento, así como el desarrollo de un camino hacia el empoderamiento.

El siguiente trabajo pretende entonces, generar una reflexión teórica, sobre el aporte del dispositivo de intervención grupal de mediación artística, en prácticas de intervención en la vejez, como herramienta posibilitadora de la apertura hacia una reelaboración narrativo identitaria.

Para ello propongo en primera instancia reflexionar en torno a la relevancia de problematizar las prácticas de intervención en la vejez, para luego en el primer capítulo, trabajar en relación a la vejez y el envejecimiento, intentando una aproximación a las narrativas prevalentes en el modelo hegemónico de vejez, introduciéndonos en otras perspectivas, como el Paradigma del Curso de la Vida, la Gerontología Crítica y la PostGerontología, como posibles líneas para problematizar la discusión sobre el envejecimiento. Planteo luego un abordaje teórico en torno al análisis narrativo y su aporte para pensar el concepto de identidad en la vejez. En el segundo capítulo abordo el concepto de dispositivo grupal y la dimensión política e institucional del mismo. En el tercer capítulo, propongo la aproximación al concepto y aportes de la mediación artística, visualizando el atravesamiento político del arte desde su potencialidad para cuestionar el orden social imperante. Finalmente en el cuarto capítulo reflexiono teóricamente sobre los resultados obtenidos a partir de la aplicación del dispositivo grupal de mediación artística ilustrando el proceso de los participantes del grupo a partir de los resultados de la intervención.

\section{¿Por qué una reflexión en torno a las prácticas de intervención en la vejez?}

A partir de la segunda mitad del siglo pasado, el avance tecnológico y científico, posibilitó el aumento de la población mayor de 60 años a nivel mundial. En el 2002 la ONU estimó que la población de personas mayores, en los próximos 50 años, alcanzará casi 2000 millones (ONU, 2002, en Pérez, 2009). Ante éste panorama nos encontramos frente a un 
gran desafío a nivel social y político, el cual asegure la calidad de vida de éste considerable sector de la población.

En este sentido es relevante una reflexión sobre las prácticas y dispositivos desde donde se aborda a este sector poblacional, las cuales evidencian el lugar desde donde pensamos el mundo y al sujeto.

Entiendo la vejez, y su modo de vivenciarla, como un proceso que se va construyendo a lo largo de toda la vida en entramados colectivos y subjetivos. Sin embargo, la misma aún sigue siendo entendida muchas veces, desde un momento estanco, relacionado al declive de lo cognitivo, social, cultural y afectivo. Estas representaciones atraviesan las prácticas de intervención con viejos, pero además, se encarnan en el sujeto obstaculizando la producción deseante singular3, la cual construye la propia vida desde el singularidad del deseo personal.

Frente a esto aparece el aporte de la grupalidad como dispositivo de transformación (Anne-Marie Duguet, 1996) con otros sujetos, y el arte como herramienta creadora y recreadora de sentidos (Friedler y Lubartowski, en Banchero \& Rovira, 2013) para la elaboración de nuevas construcciones simbólicas.

A partir del análisis del proceso de la práctica de intervención, desarrollado en la Diplomatura de Psicogerontología de la UdelaR, observamos que, partiendo de representaciones subjetivas cristalizadas sobre el envejecimiento, mediante el entrecruzamiento del dispositivo grupal con el aporte de la mediación artística, los sujetos accedieron a espacios de reflexión, adquiriendo ciertos posicionamientos críticos, en torno a representaciones hegemónicas sobre la vejez, permitiendo un camino hacia el empoderamiento. Es por ello que considero relevante reflexionar sobre esta experiencia, con el fin de generar insumos teóricos en relación al aporte del dispositivo de intervención grupal de mediación artística, en prácticas de intervención en la vejez, que como herramienta posibilite la reflexión del sujeto sobre sí mismo, la crítica a sus condiciones de existencia y la producción colectiva de nuevos sentidos.

3 Con ello me refiero desde el plano psicoanalítico a la expresión singular de uno mismo, la cual a partir de la percepción de la falta genera la potencia de la acción, constituyéndose desde el punto de vista deleuziano como devenir vital. 


\section{Capítulo 1: Envejecimiento y vejez.}

En primer término, me gustaría detenerme en visualizar cómo al hablar sobre envejecimiento y vejez, hablaré sobre la creación de una categoría, legitimada a partir de la promoción de una realidad social, hablada desde una determinada idea de verdad.

Castoriadis (1975) plantea que para cada sociedad, aquello que se constituye como problemas es inseparable del sentido problemático con la que la misma inviste al mundo. Cada sociedad, a partir de la institucionalización de ciertas prácticas, produce e instituye sentidos y significados, los cuales son sostenidos imaginariamente, estos generan que una determinada sociedad construya una forma particular de interpretar y elaborar diferentes realidades. Por esto, entiendo que la realidad dista de ser una construcción objetiva, sino, como plantea Pérez (2009) una subjetividad construida socialmente. Más adelante, retomaré la idea de cómo el imaginario social produce efectos concretos en los sujetos, afectando su identidad, al asignar significados y sentidos, orientando su deseo (Pérez, 2009).

Por lo pronto, ¿qué es lo que llevó a que la vejez sea recortada y conceptualizada como problemática social y porqué es capturada bajo determinado saber? ¿A qué intereses responde? La concepción del envejecimiento estuvo relacionada a alarmas (Pérez Díaz, 1998) que expresan los intereses de una sociedad. Podemos pensar que todo grupo aislado para su estudio y construido como problemática social, representa una perturbación para el orden social establecido, por lo tanto se lo aísla, captura, mide y se construye verdad en torno a él. Pérez Díaz (1998) refiere que las alarmas vinculadas al envejecimiento se movieron en relación a la sobrecarga del sistema sanitario, escasez de mano de obra y población económicamente productiva, y dificultades en el financiamiento del sistema de previsión social, bases que cuestionan un orden social imperante. Estas premisas fueron las que impregnaron los argumentos en torno al envejecimiento demográfico, a partir de una lógica biologicista y reduccionista, según la cual la vejez tendría los mismos efectos y cumpliría una serie de patrones estáticos, más allá de su contexto histórico social y económico. 


\section{A - Modelo hegemónico de vejez. Sus narrativas prevalentes}

Abordaré un análisis genealógico sobre aquellas narrativas que circulan en torno a modelos hegemónicos de vejez. Como mencioné anteriormente, las primeras conceptualizaciones en relación a la vejez se desarrollaron a partir de una lógica biologicista-reduccionista. Este hecho se vincula a que los primeros estudios científicos sobre la vejez surgen de la mano de la medicina en el siglo dieciocho, diagramando la construcción de un particular modelo de envejecer y de ser viejo.

La prioridad en el estudio de la vejez la van a ocupar los aspectos patológicos de la misma, observados desde el plano biológico fisiológico, relegando los procesos a nivel psicosocial (Berriel, Paredes \& Pérez, 2006). Bajo este esquema se comienza a gestar en el imaginario social, una asociación del envejecimiento a una enfermedad y no a una etapa vital en sí misma.

Al respecto Salvarezza (1988), basándose en los estudios del “ageism” de Butler (en Salvarezza, 1988) propone el término "viejismo", para definir la discriminación y segregación de la sociedad actual hacia la vejez. Esta actitud está relacionada con el ejercicio de múltiples prejuicios hacia los viejos, en función de la edad (como ejemplo: la no sexualidad en la vejez, el deterioro mental, la depresión, etc). El autor, sostiene que en esta dinámica se segrega a la vejez, y paralelamente se perpetúa el desconocimiento de ella. En la década de 1950, comienzan a producirse cambios, al incorporar estudios sociológicos sobre el envejecimiento (Lehr, 1988 en Berriel, Paredes \& Pérez, 2006), en relación a sus aspectos poblacionales y macrosociales. Sin embargo continuaría la consolidación del modelo deficitario de vejez. En el año 1961, E. Cummings y W. E. Henry (Lehr, 1988 en Berriel, Paredes \& Pérez, 2006) en relación a los aspectos sociales de la vejez, publican la llamada "teoría de la desvinculación". La premisa central de esta teoría se basa en la pérdida paulatina de interés del sujeto sobre el mundo externo a medida que va envejeciendo, replegándose sobre sí mismo, como modo de preparación para la muerte.

Esta teoría basada en procesos bio-fisiológicos, los cuales serían inherentes al envejecimiento, plantea en su fundamentación la independencia de los factores socioculturales. Más allá de la invalidación científica posterior de este planteo (Lehr, 1988 
en Berriel, Paredes \& Pérez, 2006), el mismo mantiene su influencia hasta nuestros días impregnando prácticas y discursos.

En forma casi simultánea se comienza a desarrollar la "teoría de la actividad", siendo Maddox (Lehr, 1988 en Berriel, Paredes \& Pérez, 2006), su máximo representante. Su postulado central, sostiene que a partir de la pérdida del rol social y actividades en la vejez, los sujetos deben encontrar actividades sustitutas, para así evitar la caída en un estado de alienación. Esta postura continúa en la actualidad incidiendo en las propuestas de intervención con viejos, donde el acento está puesto en el hecho de hacer algo en sí mismo, alejado del sentido que el sujeto le dé a ello. Ambas teorías, subordinando en su marco los procesos psicosociales, basadas en una epistemología positivista y causal (Berriel, Paredes \& Pérez, 2006), comparten su adscripción a un mismo modelo prejuicioso de vejez, en donde un sujeto pre diseñado, sobre el cual intervenir, se ve despojado de su capacidad crítica y reflexiva, de su ser deseante y de su generatividad autónoma.

Al partir de un modelo involutivo del ciclo vital, donde el envejecimiento se emparenta con la noción de declive, con una subordinación de los procesos psicosociales, podemos pensar: ¿qué posibilidades hay de no quedar anclado en el pasado? ¿cuál es el sentido del presente y el futuro? ¿qué anudamiento existe entre lo singular y lo colectivo? ¿qué posibilidad tiene lo novedoso, la construcción y la reconstrucción de la historia de vida en la vejez? Más adelante volveré sobre estas interrogantes.

\section{B - Posibles líneas de problematización. El paradigma del curso de la vida, gerontología crítica y Post-Gerontología.}

Como mencioné anteriormente, encontramos que las teorías gerontológicas, desarrolladas a partir de la segunda mitad del siglo veinte, producían un sujeto desde generalizaciones sobre la vejez, priorizando un modelo deficitario de la misma o en intentos de superación, mediante modelos ideales a alcanzar como el envejecimiento exitoso, a través de la actividad en sí misma, fuera del sentido que el sujeto pueda darle a ella (Zarebski, 2016).

Tanto la historicidad, como la dimensión simbólica y deseante, son excluidas de dichas teorizaciones. En las últimas décadas del siglo veinte, a partir de resultados de 
investigaciones longitudinales, se incorpora la idea de proceso, dentro del envejecimiento (Zarebski, 2016). Es así como se va conformando el Paradigma del Curso de la Vida, el cual alude a un matriz explicativa del desarrollo humano que entiende al sujeto en su devenir a lo largo de la vida y no solamente circunscrito a una etapa particular. En él, convergen influencias normativas, de carácter biológico, cronológico o derivadas del contexto histórico, con las influencias no normativas, signadas por la biografía, conformándose una multicausalidad en interacción.

En este sentido, desde el Paradigma del Curso de la Vida, la plasticidad y flexibilidad al cambio, permite la reconstrucción y resignificación de la propia identidad del sujeto en permanente devenir. Desorden como posibilidad de transformación y crecimiento. Pasado, presente y futuro se van a reinterpretar y recrear de forma nueva, distinta y no lineal (Zarebski, 2011).

Son los sujetos quienes construyen su propio curso de vida, a partir de su deseo, en una red de relaciones interconectadas, y en un determinado marco contextual.

Zarebski (2016) propone que la emergencia de este paradigma es contemporánea al avance del Paradigma de la Complejidad a nivel científico, el cual permitió la superación de un enfoque simplista propio del paradigma positivista. En este sentido Yuni (2011), plantea la imposibilidad de ciertas problematizaciones de la Gerontología Tradicional, debida a la ceguera epistémica de su posicionamiento, la cual la mantenía circunscripta a herencia de la Física y la Biología modernas.

Ahora bien, pensando como la producción de conocimiento es indisociable de la articulación con intereses, económicos, culturales y sociales, ejerciendo efectos concretos sobre la vida cotidiana de las personas: ¿podemos quedarnos anclados en aquello que deriva del deseo, y la biografía del sujeto?

Junto con las dimensiones subjetivas del envejecimiento, aparece el cuestionamiento de las relaciones de poder, en distintas corrientes teóricas enmarcadas dentro de la Gerontología Crítica, esto supone un cuestionamiento en la dimensión de la praxis, como acción comprometida con cambios prácticos, académicos y profesionales como posibilitadora de un conocimiento emancipatorio. 
El foco se encuentra en la crítica del conocimiento, la cultura, la economía y la naturaleza autorreflexiva de las teorías (Bengtson, 1997). Iacub (2001) propone la aparición de la Post-Gerontología, en el marco de las corrientes post-estructuralistas y post-modernas, dentro de la Gerontología Crítica, planteando un estudio cultural, ético y político sobre el envejecimiento.

Se parte desde la premisa de que la vejez se encuentra ordenada desde una política de edades, mediante la cual se ejerce el control social de los sujetos en relación a la categoría edad, la misma, paralelamente tendrá determinadas significaciones para cada contexto social: aquello que se designa como vejez y el tipo de problematización que se realice en torno a ella. Esto determina los modos en que será identificada y valorada, así como las acciones que se tomen sobre ella.

Partir desde la premisa de la construcción social del envejecimiento, supone trabajar con la contingencia (Iacub, 2001) identificando qué representaciones sobre la vejez rigen en un determinado contexto, las cuales dan paso a determinados discursos productores de subjetividad, creando un tipo particular de sujeto; y como autorreflexión ética del accionar teórico, a qué tipo de representaciones adherimos, lo cual podría llevar a interrogarnos sobre la pertinencia o importancia estratégica de las prácticas en éste campo.

En este sentido, tomando la idea de dispositivo desde su carácter estratégico, propuesto por Foucault (1985) podríamos interrogarnos sobre qué líneas de subjetivación hacen posible los dispositivos dispuestos en torno a la vejez.

"El pensamiento político en gerontología, tiene por lo tanto, como base ideológica, la reflexión crítica y transformación de los dispositivos etarios” (Iacub, 2001:438). En esta

línea, las reivindicaciones políticas desde el marco de la Post-Gerontología, apuntan a conseguir transformaciones en los diversos contextos (o dispositivos) en los cuales se objetive al viejo (Iacub, 2001).

Esto incluye el nivel institucional, como las relaciones personales, los discursos o formas del lenguaje o en los usos convenidos de las identidades, así como el nivel de las macropolíticas, para poder comprender los efectos subjetivos que las mismas despliegan.

\section{C - Análisis narrativo. Su aporte para pensar el concepto de identidad en la vejez}


Comenzaré este apartado aclarando que el mismo, no pretende dar cuenta de manera exhaustiva sobre el análisis narrativo, sino valorar su aporte a la hora de aproximarnos a comprender el proyecto identitario en la vejez.

En los últimos tiempos se ha generado un creciente interés por las narrativas como método de análisis en diversas disciplinas científicas, para la comprensión de fenómenos humanos y sociales (Villar, 2015). Al respecto, Bruner (en Villar, 2015) propone la diferenciación entre pensamiento lógico-paradigmático y pensamiento narrativo.

El primero se corresponde con el paradigma positivista e intenta describir, explicar y predecir los fenómenos, definiendo relaciones de causa-efecto, desarrollando leyes y teorías abstractas.

El segundo, trata de comprender los fenómenos desde la perspectiva de sus protagonistas, incorporando entonces, un punto de vista subjetivo, en la comprensión de los mismos. Este enfoque está orientado a entender el sentido que le otorgan los sujetos a su experiencia a partir de la elaboración de historias contadas a sí mismos y los demás.

La forma en cómo nos pensamos, aquello que decimos sobre nosotros y lo que dicen sobre quiénes somos, condiciona nuestro modo de experimentar, actuar y vincularnos en el mundo (Duero y Limón Arce, 2007).

Desde ésta perspectiva, el sujeto es un ser fundamentalmente hermenéutico, en la medida que intenta interpretar su experiencia, orientado a la obtención de sentido, coherencia y propósito. Esto lo consigue a partir de la elaboración de la narración y de la posibilidad de contar y compartir estos relatos (McAdams, 2013 en Villar, 2015).

Duero y Limón Arce (2007), plantean aportes en torno a la narrativa autobiográfica. La elaboración narrativa, posibilita la conjunción de experiencias pasadas, presentes y futuras en un constructo, coherente e integrado, el cual vuelve al mundo, más predecible y significativo y a nuestra experiencia y a nosotros mismos, más inteligibles. En este sentido, los mismos autores, plantean que la ausencia de un relato que dé cuenta de nuestras acciones en un marco de intenciones y propósitos, genera la imposibilidad de 
reconocimiento sobre quiénes somos, y desde allí, qué queremos, para qué, cómo y porqué. Pero ¿qué más hace falta para dotar de sentido a la existencia, pensando desde el plano de lo narrativo? Duero y Limón Arce (2007), proponen que la apertura a la incorporación de experiencias novedosas, es un aspecto esencial en este sentido. En este punto, como anteriormente planteé, nos acercamos a cuál es la relevancia de la construcciónreconstrucción y narraciones de historias de vida en la vejez.

Staudinge (en Iacub, 2010) plantea que frente a situaciones de encrucijadas vitales, se requerirá la elaboración de lo novedoso, a partir de una "reflexión vital" que posibilite una reelaboración identitaria.

En éste sentido, Berriel (2003) sostiene que lo que está en jaque en la vejez es una nueva actualización sobre el proyecto de vida. Mediante éste, el sujeto se reconoce como continuidad a lo largo de su historia, por lo tanto, desde el marco del análisis narrativo a partir del cual vengo trabajando, este proyecto está imbricado con el proyecto identitario. Podemos pensar el proyecto de vida, como una construcción en permanente reformulación, la cual incorporando lo nuevo resignifica lo anterior (Berriel, 2003), en el marco de un proceso cuya dinámica lo vuelve conflictivo. Su replanteamiento no es intrínseco a la vejez, pero adquiere obviamente, características peculiares en ésta etapa.

¿A qué responde esta peculiaridad? Bauer, y Park (en Villar, 2015) al referirse a la narrativa autobiográfica, proponen que la misma, cobra especial interés en la vejez a partir de que ésta conlleva múltiples amenazas al sentido de continuidad personal como resultado de pérdidas “asociadas a esta etapa”. La presencia de estas pérdidas generaría dificultades al encontrar sentido a este momento vital, lo que justifica la importancia de los relatos como modo de elaboración para abordarlas y mantener una idea del sí mismo.

Asimismo, Villar (2015) propone que algunos sujetos en la vejez, pueden experimentar un “cierre narrativo” (Freeman, 2011 en Villar, 2015) derivado de la imposibilidad de alojar la novedad en la narración desde la convicción prematura de que la historia de vida ha finalizado. Este cierre narrativo podría ser consecuencia de dificultades en la adaptación personal a cambios y desafíos propios de la vejez.

Ambos planteos, asociados a una explicación psicologista, resultan acotados a la hora de acercarnos a la consideración de la dimensión psicosocial del replanteamiento del 
proyecto de vida en la vejez.

Al comienzo del capítulo, planteé cómo el imaginario social produce efectos específicos en las personas, afectando su identidad, en la asignación de significados y sentidos, orientando su deseo. El proyecto de vida, es creado por el sujeto, como modo de expresión de su proyección y autonomía pero también como confirmación de los límites y normalizaciones que el disciplinamiento social le impone (Berriel, Lladó \& Pérez, en Berriel, 2003).

Por lo tanto, aquello que aparece como expresión de un proceso interno de elaboración, es también parte de un instituido social, el cual determinará la forma de despliegue del mismo en la medida que resulte funcional a las relaciones de poder imperantes. Es así como el replanteamiento del proyecto de vida, está enraizado a la inscripción social del sujeto, en un marco de fenómenos de control social que pautan los comportamientos apropiados para ciertos momentos vitales, y paralelamente definen a éstos últimos (Berriel, 2003).

Como plantea Castoriadis (1997) los sujetos en la medida que socializados, son "fragmentos hablantes y caminantes de una sociedad dada" (Castoriadis, 1997:3) encarnando las instituciones y las significaciones de la sociedad a la que pertenecen.

Desde el plano de la Post-Gerontología, se pone a jugar el análisis narrativo, en el marco de las relaciones de poder, visualizando qué narrativas sociales operan en determinado momento histórico, las cuales dan lugar y sostienen determinados mecanismos de poder en torno a la vejez (Iacub, 2001).

Villar (2015), en superación de la perspectiva individual psicologista, propone, dentro de la Gerontología Narrativa el plano sociocultural, metanarrativo, en el cual el envejecimiento aparece como construcción social, identificando relatos compartidos, posibilitando la construcción de narrativas identitarias alternativas, aquellas signadas por el mandato sociocultural hegemónico en torno a la vejez.

Según Iacub (2014) la cultura transmite e imparte determinadas expectativas, imágenes y patrones de subjetividad asociados a variantes de edad y género. Estos se constituyen en mandatos que atraviesan al sujeto, pudiendo encontrarse en tensión con sus 
narrativas singulares. La asunción del mandato cultural, establecido como la única opción validada socialmente, puede acarrear diversos mecanismos de sufrimiento psíquico, exclusión y autoexclusión a nivel social.

Es así como el sujeto aparece como construcción y agente social, y en este sentido atravesado por diversas representaciones, debe negociar el reconocimiento de su identidad (Iacub, 2001).

En este sentido, el pasaje a una nueva etapa vital, podría generar un cuestionamiento de la continuidad de la figuración del sí mismo, pudiendo producir una "ruptura biográfica” o narrativa, relacionada a la percepción de asunción del sujeto a una identidad vivenciada como desconocida, negativa o estigmatizada, vivenciándola como exterior a él, cristalizándose en una identidad no deseada bajo la asignación de quien debe ser (Iacub, 2010). La imagen de sí, entonces, es un "fragmento narrativo” (Iacub, 2011) mediante el cual se visualiza los tipos de vinculación entre el sujeto y el entorno, y dependiendo de ésta, podrá funcionar como protección, o como fragilización y ruptura.

En la misma línea Berriel (2003) propone que el proyecto de vida, podrá operar como instrumento de despliegue o de encapsulamiento de la potencia del sujeto. Pasemos a pensar el nivel de las prácticas. En este sentido, Iacub (2001) propone que el compromiso ético y político en gerontología, supone que abordemos la vejez con una mirada en lo que fue, considerando los modelos desde donde ha sido definida y capturada, pero visualizando lo que puede potencialmente ser y sobretodo, lo que busca ser.

\section{Capítulo 2: Una máquina para hacer ver y hacer hablar}

Problematizar el nivel de las prácticas, supone pensar la metodología a la que las mismas responden. Con el objetivo de reflexionar sobre el dispositivo de intervención grupal, en prácticas de intervención en la vejez abordaré dicha noción.

Como dije anteriormente, la identidad, desde el marco del análisis narrativo, es concebida como el plano donde se interceptan enunciados sociales y subjetivos. Pensemos ahora en donde transcurre la vida de estos sujetos. Para ello, nos distanciaremos de la concepción antinómica Individuo-Sociedad. 
Fernández y del Cueto (1985) proponen los grupos como espacios tácticos donde se genera la producción de efectos singulares e inéditos. No existe una realidad externa la cual influiría sobre los hechos grupales, sino que la misma, es parte del texto grupal (Fernández y del Cueto, 1985). En la constitución del grupo, entonces, estarán presentes hilos deseantes, económicos, socio- históricos y políticos.

En este sentido, Foucault (1985) propone la noción de dispositivo como la red que se establece entre elementos heterogéneos que incluyen discursos, instituciones, enunciados científicos, proposiciones filosóficas y morales, lo dicho y lo no-dicho. El carácter del dispositivo es esencialmente estratégico. Una manipulación de relaciones de fuerza. Esto inscribe al dispositivo en un juego de poder y saber, que el mismo genera, y a la vez condiciona.

Cada dispositivo distribuye lo visible y lo invisible, haciendo nacer o desaparecer el objeto que no existe sin él (Deleuze, 1999). En este sentido Deleuze (1999) plantea que el dispositivo es una máquina para hacer ver y hacer hablar. Lo constituyen por tanto, líneas de visibilidad, de enunciación y de subjetivización.

Tomando la noción de dispositivo como máquina o aparato, Jean Francois Lyotard (en Anne-Marie Duguet, 1996) describe el dispositivo como un transformador. Encontramos entonces el carácter del dispositivo, como herramienta para la provocación de transformaciones.

Lo grupal, aparece como dispositivo habilitador de lo uno, lo múltiple y lo singular. La metodología de trabajo grupal podría presentarse como habilitante entonces, de la visualización y análisis de representaciones imaginarias comunes. Estas refieren a la red de identificaciones, los mitos grupales, los hilos institucionales, como disparadores del imaginario grupal (Fernández y del Cueto, 1985), ofreciendo un espacio para la escucha y resignificación de la historia singular. Se apuesta para ello, a la conformación de sujetos protagonistas de la propia historia del grupo. Esto se va logrando, como propone Vallejo Jiménez (2006) a través de la cohesión y el sentimiento de pertenencia grupal, los cuales 
configuran la apropiación del espacio grupal.

\section{A - Dimensión política del trabajo grupal}

Todo grupo alberga aspectos repetitivos y aspectos transformadores, en una dialéctica constante. La tendencia a desarrollar uno u otro polo obedece a un sinnúmero de factores, ligados a los objetivos explícitos e implícitos de la institución -real o imaginariaen la que el grupo se inscribe, las ilusiones y mitos grupales, la red de identificaciones que ligue a sus miembros y los aspectos transferenciales que se desarrollan entre el grupo, la coordinación y la institución (Fernández y del Cueto, 1985). Por lo tanto, la posibilidad u obstaculización de elementos instituyentes a nivel grupal, está atravesada por la influencia de estos factores. En este sentido son relevantes los aportes del análisis institucional.

Para Kaes (en Markwald, 2003) la institución precede al sujeto, inscribiéndolo en sus vínculos y discursos, generando un efecto de apuntalamiento, ya que el sujeto se sostiene en ellas. La dimensión institucional, por tanto, se inscribe en la vida psíquica del sujeto, afectando su identidad. Las instituciones son productoras de subjetividad. La institución en su función de apoyatura, puede habilitar la emergencia de un sujeto creativo y lúdico, o dar lugar a un sujeto aprisionado a merced de la institución, o bien, generar una sobreimplicación de los miembros con la institución (los sujetos son la institución). Pero la institución es un proceso en movimiento y son los grupos quienes pondrán en juego ese movimiento (Markwald, 2003). Encontramos así, instituciones reproductoras de sus propias lógicas y aquellas donde emerge la construcción de una identidad singular. Institución objeto e institución sujeto, respectivamente. Una institución que intente reconstruir una versión ya vivida de la historia, no habilita la apropiación de los múltiples atravesamientos que que la conforman, obturando movimientos instituyentes.

Asimismo una institución que permita la emergencia de la novedad sin experimentar con ello una pérdida identitaria, posibilita movimientos instituyentes, generando una dialéctica estructural instituido-instituyente en la cual se pueda seguir produciendo efectos (Markwald, 2003). 
En este punto, es interesante retomar el aporte de la noción de dispositivo grupal como herramienta para la provocación de transformaciones, facilitadora de la emergencia de movimientos instituyentes. Al decir de Foucault (en Heredia, 2012) el dispositivo es la forma política que surge como solución pragmática para dar una repuesta de origen práctico y ético-político. La emergencia de un dispositivo entonces, obedece a una función estratégica dominante.

Asimismo, su surgimiento se enmarca en instituciones cerradas, favoreciendo la regeneración de sus métodos operativos, y la reconfiguración organizacional de la misma (Heredia, 2012).

\section{Capitulo 3: El arte como herramienta. La mediación artística}

Continuando el trabajo sobre la noción de dispositivo, reflexionaré sobre la concepción de mediación artística, la cual parte de la idea del Arte como herramienta, colocando el acento en lo que la experiencia artística posibilita, al margen de los resultados del producto artístico.

La mediación artística incorpora algunos conceptos abordados desde el plano de la pedagogía, la psicología y el trabajo social: el desarrollo integral del sujeto y el rescate de las potencialidades del mismo, la elaboración simbólica, y la toma de conciencia de la situación actual e inicio de un proceso hacia la transformación. La actividad artística conecta al sujeto con su identidad singular y socio-cultural, habilitando la revisión del imaginario, mediante el acceso al universo simbólico (Moreno González, 2010).

En este sentido, Rojas y Sternbach (en Moreno González, 2010) plantean que no es posible la elaboración sin memoria, y el acceso a la simbolización va ligado a la resignificación de la propia historia. Es entonces como esta herramienta habilita la creación de nuevas formas de significación, en la medida que posibilita un camino para establecer redes simbólicas novedosas (Friedler \& Lubartowski en Banchero \& Rovira, 2013). La experiencia artística facilita entonces, un posicionamiento crítico del sujeto, ante su realidad. 


\section{A - Dimensión política del arte}

Rancière (en Bugnone, 2014) plantea que la obra de arte crea un mundo, en la medida que funda un nuevo sistema de significados. La misma representa una propuesta de nueva y distinta sistematización del mundo.

La producción artística adquiere entonces, la potencialidad de cuestionar el orden social dominante, en la medida de que habilita lo novedoso en relación a los usos, prácticas y discursos hegemónicos, con valores materiales y simbólicos desde los cuales es posible plantearse modos alternativos o instituyentes de representar, pensar e intervenir en el mundo.

A nivel político, entonces, el arte encuentra su potencia, desde su capacidad no reproductiva, ajena a los sentidos disponibles. Esta actividad rompe la “configuración sensible”, es decir lo que se establece como ley y que determina el orden de los cuerpos, sus tareas asignadas, así como “lo visible y lo decible” (Rancière en Bugnone, 2014: 6).

En este punto, retomo el concepto de dispositivo de Foucault (1985), al interrogarme sobre cuál es sentido de las prácticas devenidas de la experiencia artística, o al decir de Deleuze (1999), qué líneas de visibilidad o enunciación promueven las mismas.

De esta forma Brea (2009) propone que el desafío principal de las prácticas culturales en el sistema actual, reside en encontrar su sentido a partir de su capacidad para desplegarse como dispositivos de criticidad, propiciando el cuestionamiento de órdenes dominantes, mediante la generación de modelos alternativos como instrumentos que habiliten nuevas producciones de subjetividad y narrativa.

\section{Capitulo 4: Metodología}

\section{El dispositivo en marcha}

A continuación desarrollaré tanto la metodología cuantitativa de recogida y análisis de datos de la intervención; como la metodología cualitativa utilizada en los diversos encuentros (taller literario, cine foro), así como las categorías teóricas desde donde se analizarán los datos. 


\section{Población objetivo}

Personas mayores según la legislación nacional (65 años y más), socios de una asociación de jubilados y pensionistas nucleada a ONAJPU (Organización Nacional de Jubilados y Pensionistas del Uruguay) que participan desde el 2015 en el llamado “Taller de Estimulación Cognitiva”, que coordinamos junto a una colega en dicha asociación. El grupo estuvo compuesto por 10 integrantes: 9 mujeres y 1 hombre, pertenecientes a jubilados y/o familiares que desarrollaron actividad laboral en el sector financiero.

Debido a que se trabaja con este grupo desde mediados del 2015, se les plantea a sus miembros la participación voluntaria (mediados de 2017) en la intervención llevada adelante en el marco de la Diplomatura en Psicogerontología, especificando los objetivos de la misma, el uso de mediadores artísticos en los diversos encuentros y la elaboración de un trabajo final respetando la confidencialidad de los y las participantes.

Asociación de jubilados y pensionistas.

La Asociación, surge en 1953 por un grupo de jubilados del sector financiero. La misma, no tiene fines de lucro, y se plantea como misión “asegurar” a sus asociados un "bienestar digno” y un "nivel de vida decoroso”, el fomento de actividades culturales, sociales y económicas, servicios cooperativos y médicos, así como promover una “elevación” tanto “moral” como intelectual” de sus socios. Por otro lado, se especifica que la misma no tiene ningún tipo de filiación o alineación política, religiosa o filosófica.

\section{A - Descripción y desarrollo de lo realizado}

Quisiera detenerme brevemente en especificar que el dispositivo de intervención se planteó desde un enfoque narrativo, haciendo foco en las historias de vida de los participantes desde el plano del contenido de los relatos y desde la construcción del relato como proceso interactivo, entendiendo la narrativa como construida socialmente y como forma de acción social. Enfatizamos en cómo esos relatos se elaboran y cómo a partir de las narraciones los sujetos logran determinados efectos performativos (Phoenix, Smith \& 
Sparkes, en Villar \& Serrat, 2015).

\section{- Primer encuentro}

\section{Dinámica literaria narrativa}

Fundamentación: Se toma el aporte de la escritura en la medida que desde una perspectiva comunicativa, o interpersonal, habilita la interacción y comunicación con otros; y representativa o ideacional, posibilitando la expresión de conocimientos, ideas y afectos. La escritura aparece como instrumento de toma de conciencia, desarrollo y de construcción del pensamiento sobre el sujeto y su realidad (Bustos, 2009). Se pretende habilitar un espacio de reflexión en relación al proceso de envejecimiento a partir de la simbolización por medio de la escritura.

Se elige en el primer encuentro el uso de este mediador artístico, en la medida que la escritura es un medio familiar y habilita un primer momento de intimidad y reflexión personal.

La frase elegida de la autora Simone de Beauvoir (1908-1986) : "Las arrugas de la piel son ese algo indescriptible que procede del alma”.

La justificación del uso de una cita, proveniente de Simone de Beauvoir, se basa en la provocación que podría generar en un grupo -que hemos observado con componente de pensamiento conservador- la elección de un personaje antagónico (filósofa, feminista, atea). La elección de la cita se justifica en la medida que podría evocar representaciones de la vejez tanto a nivel físico-orgánico como emocional-afectivo.

Se les plantea la consigna: ¿cómo continuaría este texto? Se especifica que no hay una única forma de continuarlo y que no será evaluado. Finalmente se procede a compartir verbalmente lo realizado por cada miembro, especificando que se respetará quien no decida hacerlo.

- Segundo encuentro

Aplicación de cuestionario

Fundamentación: A partir de la aplicación del cuestionario anónimo, se pretende indagar la concepción de vejez imperante en el grupo.

- Tercer encuentro 
Reflexiones sobre resonancias grupales

Fundamentación: Se pretende habilitar el espacio de reflexión en relación al proceso de envejecimiento a partir de la escucha de las resonancias grupales, en relación a la dinámica propuesta en el primer encuentro.

\section{- Cuarto encuentro}

\section{Debate sobre la escritora Simone de Beauvoir}

Fundamentación: Dado los avances a nivel de la cohesión grupal, introducimos la dinámica de debate grupal.

La justificación de la recaudación de información sobre Simone de Beauvoir se fundamenta en que la misma es un personaje antagónico en relación a las representaciones sobre la vejez presentadas hasta el momento en el grupo.

\section{- Quinto encuentro}

\section{Dinámica literaria narrativa}

Fundamentación: Se pretende habilitar un espacio de reflexión en relación al proceso de envejecimiento a partir de la problematización de dos textos periodísticos: "6 fascinantes consejos para ser un adulto mayor saludable" ${ }^{4}$ y "Vidas plenas, más allá de la edad" generando un espacio de problematización en relación a diversas posturas a la hora de concebir la vejez.

La justificación de su elección se basa en las representaciones opuestas que subyacen en ambos textos en relación a la vejez. Para ello se organizan subgrupos de manera aleatoria con tres integrantes cada uno, otorgándole a cada participante los dos textos.

\section{- $\quad$ Sexto encuentro}

Dinámica literaria narrativa. Continuación y debate de la dinámica narrativa del 5to encuentro, a partir de una puesta a punto y discusión grupal en relación a los textos

4 Recuperado de: https://www.salud180.com/adultos-mayores/6-fascinantes-consejos-para-ser-unadulto-mayor-saludable

5 Recuperado de: https://www.clarin.com/opinion/vidas-plenas-alla-edad_0_B1lW5Ihhe.html 
trabajados el encuentro anterior.

\section{- $\quad$ Séptimo encuentro}

\section{Dinámica narrativa autobiográfica. Anécdotas personales.}

Fundamentación: Se toma el relato anecdótico autobiográfico, pretendiendo habilitar un espacio de reflexión sobre la identidad personal, desde el entendido de que la forma en que las personas construyen sus relatos autobiográficos condiciona sus formas de pensarse y pensar al mundo (Duero y Limón Arce, 2007). Para ello se le pide a cada participante que elabore una anécdota sobre su infancia y otra sobre su adolescencia-adultez, para luego compartir verbalmente cada una de las anécdotas.

Se invita a cada participante a que extraiga nota de aquellas palabras que le resuenen del relato del otro.

Se elige este momento, dado los avances a nivel de la cohesión grupal.

\section{- $\quad$ Octavo encuentro \\ Dinámica narrativa colaborativa}

Fundamentación: Se toma la narrativa colaborativa, en la medida que permite propiciar la escucha y reflexión con otros, pretendiendo habilitar un espacio de reflexión sobre la identidad y resignificación de la historia personal (Mercer, en Bustos 2009). Se propone armar una narración a nivel subgrupal, que refleje el sentir en la vejez, con las palabras que resonaron de las anécdotas relatadas por los compañeros en el encuentro anterior. Se elige este momento dado los avances a nivel de la cohesión grupal.

\section{- $\quad$ Noveno encuentro}

Cine foro

Fundamentación: se procura a través de un medio conocido como es el cine y la selección específica de la película "Las chicas de la lencería”, generar la posibilidad de que aparezcan mecanismos de identificación que permitan en los participantes la búsqueda de elementos que guardan relación con su situación y/o experiencia vital y la posibilidad de reflexionar sobre la propia vejez en sus formas hegemónicas o alternativas de transitarla. 
Particularmente, el cine interactivo, en la experiencia grupal, considerado como motor de la relación intra e interpersonal, posibilita a partir de la proyección, el intercambio de experiencias con otros y la identificación con estos (Lauretti, González \& Flores, 2009). En ese sentido se pretende habilitar la problematización en torno a la autonomía, sexualidad y proyectos vitales en la vejez.

Para ello se proyectó la película y se plantea realizar una reflexión individual sobre la misma.

\section{- $\quad$ Décimo encuentro}

Re aplicación del cuestionario inicial y reflexiones sobre el proceso

Fundamentación: Se procura en este último encuentro, reflexionar sobre las resonancias del proceso, evaluarlo y dar cierre al mismo.

\section{B - Recogida y análisis de datos cuantitativos}

Con el objetivo de generar una aproximación, a comprender la utilidad de la inclusión de mediadores artísticos en estrategias de intervención grupal en la vejez, trabajé a partir del informe de la práctica de intervención de la Diplomatura en Psicogerontología.

Desde el plano cuantitativo, se trabajó a partir de la aplicación, evaluación y análisis de un cuestionario, diseñado por el equipo de intervención, aplicado al inicio del proceso, para indagar la concepción de vejez imperante en el grupo, y al final del mismo, para evaluar posibles cambios a nivel subjetivo.

El análisis de contenido cuantitativo tuvo como fin acotar la información y medir la variabilidad (Hernández Sampieri, R. et al, 2004) en las representaciones sociales sobre la vejez luego de transcurrido el proceso de intervención. Para el diseño del mismo, se tomó como referencia, los aportes del Test de Frases Incompletas para Identificar Representaciones y Actitudes ante la Vejez- FIIRAV- (Quintanar y García, 2013). El mismo es un instrumento de evaluación de representaciones y actitudes ante la vejez con el fin de elaborar un perfil psicogerontológico a partir de la adultez. 
Se incluyó además el análisis de representaciones sociales sobre la perspectiva de género en la vejez, no contemplada en el FIIRAV.

- Las áreas indagadas fueron:

1) Concepción y reconocimiento de la vejez - Refiere al conjunto de ideas, expresiones, afectos, acciones o hechos con los cuales la persona da referencia de lo que piensa sobre la vejez en general (Quintanar y García, 2013). Se incluyen las siguientes preguntas:

¿Qué considera ser viejo?

¿Qué es para usted envejecer?

¿Cómo ve usted cómo es ser viejo en el año 2017?

¿Desde qué edad considera que alguien es viejo?

2) Percepción personal del propio envejecer - Refiere al conjunto de ideas, reconocimiento de indicios personales, expresiones, afectos y acciones con los cuales la persona manifiesta lo que piensa o percibe sobre su vejez (Quintanar y García, 2013). Se incluyen las siguientes preguntas:

¿Qué cosa ve como negativas en el proceso de envejecimiento?

¿Qué cosas ve positivas en el proceso de envejecimiento?

3) Perspectiva de género en la vejez - Refiere al conjunto de ideas, expresiones, afectos y acciones con los cuales la persona manifiesta lo que piensa o percibe sobre su perspectiva de género en la vejez. Se incluyen las siguientes preguntas:

¿Cómo considera que es envejecer siendo varón en Uruguay?

¿Cómo considera que es envejecer siendo mujer en Uruguay?

4) Recreación y tiempo libre - Refiere al conjunto de ideas, expresiones, afectos y hechos con los cuales la persona manifiesta lo que representa tener tiempo disponible y de recreación (Quintanar y García, 2013). Se incluyen las siguientes preguntas:

Completar la frase: "el tiempo libre en la vejez, es...”

Completar la frase: "la diversión en la vejez, es..."

5) Salud y bienestar - Refiere al conjunto de ideas, expresiones, hechos con los cuales la persona percibe su estado de salud (Quintanar y García, 2013). Se incluye la siguiente pregunta:

Completar la frase: "la enfermedad en la vejez, es..."

6) Sexualidad - Refiere al conjunto de ideas, expresiones, afectos y hechos con los cuales 
la persona identifica la sexualidad en la vejez (Quintanar y García, 2013). Se incluye la siguiente pregunta:

\section{Completar la frase: "la sexualidad en la vejez es..."}

7) Imaginario y representación de la vejez - Refiere al conjunto de ideas, expresiones, afectos los cuales la persona, o el grupo social en el cual está inserto, expresa opiniones y creencias acerca de la vejez (Quintanar y García, 2013). Se incluyen las siguientes preguntas:

¿Cómo considera que lo ven los demás?

¿Cómo veía usted el ser viejo cuando era niño o en la juventud?

En otros países, ¿cómo se imagina que es el envejecer?

¿Se siente dependiente en relación a su entorno?, ¿en qué circunstancias

Escala para evaluación de las respuestas a cada una de las frases (Quintanar y García, 2013):

Positivo- presenta respuestas adecuadas en relación a las áreas indagadas, manifestando respuestas satisfactorias y adaptativas.

Negativo- presenta conflictos emocionales e insatisfacción en el área indagada. Incluye aspectos agresivos y/o depresivos.

\section{C - Recogida y análisis de datos cualitativos}

Sumado a la aplicación de métodos cuantitativos, se analizan los datos extraídos a partir del registro de los emergentes grupales durante el proceso de intervención, a través de la reflexión teórica de algunas viñetas, las cuales ilustran los relatos elaborados en el pasaje de los participantes por el dispositivo. La inclusión de dichas viñetas, más que responder una cuestión estadística, persigue la relevancia y reflexión teórica y su potencial de análisis desde las nociones de:

- Dispositivo grupal: entendido desde su carácter estratégico (Foucault, 1985) como herramienta para la visibilización y análisis de representaciones imaginarias comunes, como disparadores del imaginario grupal (Fernández y del Cueto, 1985), 
y provocación de transformaciones (Jean Francois Lyotard en Anne-Marie Duguet, 1996), ofreciendo un espacio para la escucha y resignificación de la historia singular.

- Mediadores artísticos: entendidos como herramienta para la creación de nuevas formas de significación, en la medida que posibilitan un nuevo camino para establecer redes simbólicas (Friedler y Lubartowski en Banchero \& Rovira, 2013). A partir de la incorporación de técnicas artísticas se puede comprender como la percepción del sujeto y del mundo que lo rodea, son representaciones atravesadas por el entorno y la cultura, por lo cual, son conceptos revisables y dinámicos.

La experiencia artística facilita entonces, que el sujeto se posicione críticamente ante su realidad (Rojas y Sternbach, en Moreno González, 2010).

- Identidad narrativa: Conceptualizada desde el marco del análisis narrativo, la identidad aparece como el plano donde se interceptan enunciados sociales y subjetivos. El sujeto es concebido como construcción y agente social (Iacub, 2001), desde esta perspectiva los sujetos alcanzarán mayores niveles de empoderamiento en la medida en que se apropien de sus proyectos, reconociendo los mandatos que los atraviesan y devengan sujetos en transformación permanente (Berriel, 2003).

\section{Capítulo 5: Resultados}

\section{Análisis del cuestionario: Representaciones sobre la vejez y articulación con emergentes del proceso de intervención}

En la primera aplicación del cuestionario, debido a inasistencias de 3 integrantes, 7 miembros del grupo, participaron de manera anónima en el llenado del mismo. Como forma de obtener la misma muestra representativa, se realiza la aplicación final, a los mismos integrantes del grupo.

Análisis y evaluación por áreas

Concepción y reconocimiento de la vejez.

\begin{tabular}{|c|l|l|}
\hline Preguntas & \multicolumn{1}{|c|}{$1^{\circ}$ aplicación } & Aplicación final \\
\hline ¿Qué considera usted que es & $100 \%$ negativo & $57 \%$ negativo \\
\hline
\end{tabular}




\begin{tabular}{|l|l|l|}
\hline ser viejo? & & $43 \%$ positivo \\
\hline $\begin{array}{l}\text { ¿Qué es para usted } \\
\text { envejecer? }\end{array}$ & $\begin{array}{l}85 \% \text { negativo } \\
15 \% \text { positivo }\end{array}$ & $\begin{array}{l}57 \% \text { negativo } \\
43 \% \text { positivo }\end{array}$ \\
\hline $\begin{array}{l}\text { ¿Cómo ve usted como es ser } \\
\text { viejo en el año 2017? }\end{array}$ & $\begin{array}{l}57 \% \text { negativo } \\
43 \% \text { positivo } \\
71 \% \text { positivo }\end{array}$ \\
\hline $\begin{array}{l}\text { ¿Desde qué edad considera } \\
\text { que alguien es viejo? }\end{array}$ & $\begin{array}{l}57 \% \text { negativo } \\
43 \% \text { positivo }\end{array}$ & $100 \%$ positivo \\
\hline
\end{tabular}

En relación al área concepción y reconocimiento de la vejez se observa, en la primera toma un predominio de las respuestas negativas, apegadas al declive orgánico, que expresan una conflictiva emocional frente a la concepción de la vejez:

etapa en que el organismo ya no es joven, se va deteriorando, estar gastado(...) no servís, sentirse disminuido, que tu tiempo se fue

Luego de transcurrida la intervención se genera un cambio expresado en un aumento de respuestas satisfactorias:

Haber vivido muchos años, avanzar en los tiempos y aprender.

Consideramos este cambio en relación a la reflexión en torno a algunas representaciones hegemónicas del envejecimiento, a lo largo del proceso de intervención. Si bien no hay un desprendimiento total de representaciones vinculadas a lo apegado de lo orgánico y el declive, al final del proceso se logró la visualización de la vejez como devenir singular a lo largo del curso de vida.

Percepción personal del propio envejecer.

\begin{tabular}{|l|l|l|}
\hline \multicolumn{1}{|c|}{ Preguntas } & \multicolumn{1}{|c|}{$1^{\circ}$ aplicación } & \multicolumn{1}{c|}{ Aplicación final } \\
\hline $\begin{array}{l}\text { ¿Qué cosa ve como negativas } \\
\text { en el proceso de } \\
\text { envejecimiento? }\end{array}$ & $100 \%$ negativo & $100 \%$ negativo \\
\hline $\begin{array}{l}\text { ¿Qué cosas ve positivas en el } \\
\text { proceso de envejecimiento? }\end{array}$ & $\begin{array}{l}15 \% \text { negativo } \\
85 \% \text { positivo }\end{array}$ & $\begin{array}{l}15 \% \text { negativo } \\
85 \% \text { positivo }\end{array}$ \\
\hline
\end{tabular}

En relación al área percepción personal del propio envejecer, se observa el aumento 
de aspectos positivos y adaptativos luego de transcurrida la intervención, en la apreciación del propio envejecimiento. Los mismos están ligados al valor de la experiencia en el vínculo con el otro. En la aplicación final del cuestionario, se encuentran repuestas como:

ser capaz de comprender las actitudes de los otros seres humanos, ser más paciente, aprender a no juzgar a priori.

Sin embargo se mantuvo constante la percepción de aspectos negativos en relación al envejecimiento, vinculados mayormente a elementos orgánicos:

miedo a enfermar; vienen las enfermedades; se es más lento, se oye y se ve menos y a veces afecta el cerebro; la salud a veces es un problema, los mayores empiezan a aislarse y no se interesan por nada

Se considera que si bien el grupo adquiere ciertos posicionamientos críticos en torno a representaciones hegemónicas sobre la vejez, se da una dialéctica constante de apertura reflexiva, seguida por la reaparición de elementos conservadores, arraigados a la identidad cristalizada sobre el envejecimiento.

Perspectiva de género en la vejez

\begin{tabular}{|c|c|c|}
\hline Preguntas & $1^{\circ}$ aplicación & Aplicación final \\
\hline $\begin{array}{l}\text { ¿Cómo considera que es } \\
\text { envejecer siendo hombre en } \\
\text { Uruguay? }\end{array}$ & $100 \%$ negativo & $100 \%$ negativo \\
\hline $\begin{array}{l}\text { ¿Cómo considera que es } \\
\text { envejecer siendo mujer en } \\
\text { Uruguay? }\end{array}$ & $\begin{array}{l}57 \% \text { negativo } \\
43 \% \text { positivo }\end{array}$ & $\begin{array}{l}\text { 29\% negativo } \\
71 \% \text { positivo }\end{array}$ \\
\hline
\end{tabular}

En relación a la perspectiva de género en la vejez, se encuentra, que no se logra un cambio en la perspectiva de género vinculada al envejecimiento masculino, luego de transcurrida la intervención.

Las respuestas están referidas en su mayoría al conflicto en el hombre, en la posibilidad de adaptación a los cambios a partir de dificultades en la expresión emocional:

lo aceptan menos; el hombre tiene menos decisión para integrarse a sus pares, a veces se aísla y se deprime 
Aparecen elementos vinculados a la identidad masculina, a partir de la vida laboral y productivo-económica, y la dificultad en el duelo de éstas pérdidas en la vejez. En palabras de un varón del grupo:

para el hombre es más difícil envejecer a partir de la jubilación (...) porque se ven con las manos vacías y poco útil; si no tenes dinero y memoria para manejarte con sentido común, más alguien que se ocupe de tí, más vale no envejecer

A lo largo del proceso, se hallan elementos referidos a cómo las pérdidas a nivel físico (fuerza, estabilidad, etc) en el varón cobran mayor importancia que en la mujer, acarreando angustia y modos de ocultarla. Éstos también se ven reflejados en la aplicación del cuestionario. En palabras de una mujer del grupo:

son orgullosos y si ven que un joven se levanta en el ómnibus para darle el asiento no lo toman, siguen parados, quieren hacer creer que son jóvenes!

Se considera que la presencia de una única figura masculina en el grupo, portavoz de los aspectos más conservadores a nivel grupal, podría haber influenciado en la no posibilidad de cambio de perspectiva vinculado a la emergencia de elementos positivos en la vejez masculina.

Sobre la perspectiva de género en envejecimiento en la mujer, se encuentra un aumento de respuestas satisfactorias luego de transcurrido el proceso de intervención.

Al inicio del proceso, se hallaron elementos referidos a la falta de autonomía relacionada a los cuidados centrados en la mujer. En este sentido, en la primera toma del cuestionario se reflejan respuestas como:

me encanta cuidar a mis nietos pero a veces no me deja hacer cosas que quiero

La falta de autonomía se ve atravesada por la debilidad que conllevaría la viudez en la mujer:

desde que quedé viuda, mis hijas me andan más arriba, como controlando 
Estos elementos se constatan durante la apertura reflexiva posibilitada en el proceso sobre la desigualdad de género en la vejez. Es así como en uno de los encuentros aparecen comentarios como:

quieren imponerme su manera de pensar, sobre todo a veces del sexo masculino, me pasa con mi yerno, que es bastante controlador

Se considera que el aumento de respuestas satisfactorias en relación al ser mujer en la vejez, podría estar vinculada a la visualización, durante el proceso de intervención, de otros modos de ser mujer alternativos a lógicas conservadoras. Se observa en los últimos encuentros respuestas como:

La actriz principal (...) comienza a hacer todo lo que siempre quiso y postergó por la atención a la vida hogareña, liberada de una vida pendiente a los demás, se da cuenta que puede disfrutar con lo que realmente desea

Se encuentran en el cuestionario respuestas como

después de enviudar tuve más libertad; estoy empezando a pedir que me respeten mis decisiones

Recreación y tiempo libre

\begin{tabular}{|l|l|l|}
\hline \multicolumn{1}{|c|}{ Preguntas } & \multicolumn{1}{|c|}{$1^{\circ}$ aplicación } & \multicolumn{1}{c|}{ Aplicación final } \\
\hline El tiempo libre en la vejez & $57 \%$ positivo & $85 \%$ positivo \\
es... & $43 \%$ negativo & $15 \%$ negativo \\
\hline La diversión en la vejez es... & $\begin{array}{l}71 \% \text { positivo } \\
29 \% \text { negativo }\end{array}$ & $\begin{array}{l}71 \% \text { positivo } \\
29 \% \text { negativo }\end{array}$ \\
\hline
\end{tabular}

En cuanto al área recreación y tiempo libre, se observa un aumento en la valorización del tiempo libre. Se encuentran en el cuestionario, respuestas como:

hermoso, se puede hacer todo lo pendiente

En un grupo, en el cual inicialmente el trabajo colectivo ofrecía resistencias, el disfrute aparece ligado finalmente, a poder compartir con otro: 
es bueno integrarse a grupos y además de la familia, tener buenas amistades, con quienes compartir; estas reuniones me han socializado mucho

Salud y bienestar

\begin{tabular}{|l|l|l|}
\hline \multicolumn{1}{|c|}{ Preguntas } & \multicolumn{1}{|c|}{$1^{\circ}$ aplicación } & \multicolumn{1}{c|}{ Aplicación final } \\
\hline $\begin{array}{l}\text { La enfermedad en la vejez } \\
\text { es... }\end{array}$ & $100 \%$ negativo & $100 \%$ negativo \\
\hline
\end{tabular}

En relación al área salud y bienestar, se observa que no se logra una modificación en la percepción de la misma luego de transcurrida la intervención.

La concepción de vejez permanece ligada a la enfermedad y al temor a la pérdida de autonomía. Se hallan en el cuestionario respuestas como

miedo a depender de otros; en la vejez se da la enfermedad y limita al no poder realizar determinadas cosas que antes disfrutaba

No aparece una movilización de aspectos subjetivos, vinculados al modelo tradicional de envejecimiento (Berriel, Paredes \& Pérez, 2006) en torno al binomio vejezenfermedad.

Sexualidad. Primera aplicación

\begin{tabular}{|l|l|l|}
\hline \multicolumn{1}{|c|}{ Preguntas } & \multicolumn{1}{|c|}{$1^{\circ}$ aplicación } & \multicolumn{1}{c|}{ Aplicación final } \\
\hline $\begin{array}{l}\text { La sexualidad en la vejez } \\
\text { es... }\end{array}$ & $\begin{array}{l}\text { 85\% negativo } \\
15 \% \text { positivo }\end{array}$ & $\begin{array}{l}29 \% \text { negativo } \\
71 \% \text { positivo }\end{array}$ \\
\hline
\end{tabular}

$\underline{\text { Se observa un aumento de respuestas satisfactorias en la vivencia de la sexualidad, }}$ luego de trascurrida la intervención. Se considera que éste aumento, estaría ligado a vivenciarse como seres sexuales en tanto la necesidad de reconocerse y ser reconocidos como seres autónomos, lograda a partir de la apertura reflexiva.

Se observa en la aplicación final del cuestionario, respuestas como

influyen los tristes límites que las familias imponen, sin darse cuenta de la intimidad que necesitan las parejas mayores y peor cuando son los residenciales, que desconocen la sexualidad en la ancianidad. Otra paradoja 
Imaginario y representación de la vejez

\begin{tabular}{|l|l|l|}
\hline \multicolumn{1}{|c|}{ Preguntas } & \multicolumn{1}{|c|}{$1^{\circ}$ aplicación } & \multicolumn{1}{|c|}{ Aplicación final } \\
\hline $\begin{array}{l}\text { ¿Se siente dependiente en } \\
\text { relación a su entorno? ¿En } \\
\text { qué circunstancias? }\end{array}$ & $\begin{array}{l}57 \% \text { negativo } \\
73 \% \text { negativo } \\
43 \text { positivo }\end{array}$ \\
\hline $\begin{array}{l}\text { ¿Cómo considera que lo ven } \\
\text { los demás? }\end{array}$ & $\begin{array}{l}85 \% \text { negativo } \\
15 \% \text { positivo }\end{array}$ & $\begin{array}{l}43 \% \text { negativo } \\
57 \% \text { positivo }\end{array}$ \\
\hline $\begin{array}{l}\text { ¿En otros países cómo se } \\
\text { imagina que es el envejecer? }\end{array}$ & $\begin{array}{l}43 \% \text { negativo } \\
57 \% \text { positivo } \\
29 \% \text { positivo }\end{array}$ \\
\hline $\begin{array}{l}\text { ¿Cómo veía usted el ser viejo } \\
\text { cuando era niño o en la } \\
\text { juventud? }\end{array}$ & $\begin{array}{l}57 \% \text { negativo } \\
57 \% \text { positivo } \\
43 \% \text { positivo }\end{array}$ \\
\hline
\end{tabular}

En relación al área imaginario y representación en la vejez, se observan los siguientes cambios, luego de transcurrida la intervención:

Al comienzo del proceso el grupo reflexiona acerca de cómo la mirada del otro, marca el inicio de la "vejez". Se hallan en los primeros encuentros, expresiones como:

Te das cuenta que tenés una edad, cuando el guarda del ómnibus pide a gritos 'un asiento para la abuela'

$\underline{\text { Se observa el aumento de respuestas favorables en torno a la percepción de la }}$ mirada del otro. En la aplicación final del cuestionario ante la pregunta, “¿cómo considera que lo ven los demás?”, aparecen respuestas como:

me ven vital; llena de sueños y esperanzas

Se observa el descenso de respuestas negativas en relación a la dependencia del otro, sin embargo sigue vinculada fundamentalmente a situaciones de enfermedad. Aparecen en el cuestionario respuestas como

me siento dependiente cuando la salud no es muy buena y se necesita ayuda

En cuanto al imaginario de cómo es envejecer en otro país, aparece al comienzo del 
proceso una idealización, viéndose modificado, en tanto disminuye, luego de la intervención.

Se considera que la apertura reflexiva promovió la visualización de la influencia del contexto socio histórico, en el armado de representaciones sobre la vejez:

depende del país, en los más modernos valoran al anciano. En tribus o países más tradicionales, valoran más a los ancestros

\section{Capítulo 6: Interpretación}

\section{A - La "realidad" desde donde se veían, hablaban y vivenciaban}

"Porque yo soy del tamaño de lo que veo, y no del tamaño de mi estatura" (Pessoa, 1997).

Estamos viejos para esto.

No sé si voy a poder con esto.

¿Otra vez hay que trabajar en grupo?

Faltan hombres de verdad como los de antes, que lleven el país adelante, ¿̇a dónde va a ir parar todo esto?.

Estas fueron algunas de las expresiones que escuchábamos en el grupo de viejos que participaban de los talleres de estimulación cognitiva en el año 2015.

Por su parte desde la institución donde está inserto el grupo, observamos rigideces en la comunicación entre sus miembros y con el resto de la comunidad. Es así como por ejemplo frente a solicitudes nuestras sobre un posible cambio horario, encontramos inflexibilidad a la hora de concretar el mismo, dificultades para contactar con secretaría, hermetismo en la difusión de actividades, negativa a la hora de plantear actividades de intercambio y recreación.

Desde la directiva institucional, además se nos comentaba acerca de los obstáculos que encontraba la organización para crecer como tal, al no lograr captar nuevos socios o no lograr la participación activa de los ya existentes. Este planteo se realizaba desde la queja, sin abordar a una postura reflexiva hacia la interna de la institución.

En éste sentido, embarcamos en una propuesta de apertura a un espacio de crítica y reflexión sobre la identidad en la vejez, en el marco de la práctica de intervención de la Diplomatura, resultaba un gran desafío, pero comenzamos a andar. 
Al comienzo de la intervención se evaluó la concepción de envejecimiento imperante en el grupo, a partir de la escucha de resonancias grupales y la aplicación del cuestionario cuantitativo para identificar las representaciones subjetivas grupales ante la vejez. Se encontró, la existencia de una concepción sobre la vejez, arraigada a un modelo hegemónico de envejecimiento, en donde los sujetos encarnaban aspectos vinculados al viejismo (Butler, en Salvarezza 1988) predominando una imagen desvalorizada, patológica y prejuiciosa de la vejez:

Vienen las enfermedades.

Se es más lento, se oye y se ve menos y a veces afecta el cerebro

La salud es un problema, los mayores empiezan a aislarse y no se interesan por nada

Observamos en relación al área salud y bienestar, indagada desde la aplicación del cuestionario, una concepción de vejez ligada a la enfermedad y al temor a la pérdida de autonomía. Ante la premisa de completar la frase: "La enfermedad en la vejez es..." se hallan en el cuestionario respuestas como:

Miedo a depender de otros.

En la vejez se da la enfermedad y limita al no poder realizar determinadas cosas que antes disfrutaba" 7.

En este sentido tomaban relevancia los aspectos vinculados a la vivencia de declive desde el plano de lo biológico-fisiológico, subordinando el atravesamiento de los procesos a nivel psicosocial.

Cabe recalcar que este grupo se sostuvo, desde los participantes y desde nosotros como coordinación, durante dos años, bajo la premisa de realizar actividades de estimulación cognitiva, mostrando resistencias a la hora de pensarse(nos) más allá del mantenimiento de un funcionamiento cognitivo considerado adecuado desde cierto saber imperante.

Como análisis y crítica de la propia práctica, diré que por el año 2015, cuando comenzábamos a trabajar con estos viejos, las actividades si bien intentaban la superación

7 Es interesante mencionar que una de las pocas representaciones subjetivas que no presentaron modificaciones luego de transcurrido el proceso de intervención fue el área salud y bienestar, la cual merecería un análisis particular. 
del binomio vejez- declive, eran pensadas desde un modelo deficitario, intentando alcanzar modelos ideales de envejecimiento exitoso, dejando por fuera la historicidad y la dimensión simbólica y deseante del sujeto (Zarebski, 2016).

Desde el ámbito de la Gerontología Crítica, Estes (en Iacub, 2001) propone una crítica hacia lo que denominó la "empresa del envejecimiento" refiriéndose a la multiplicidad de profesionales e instituciones que abordaron el envejecimiento desde la oferta de un conglomerado de actividades y propuestas desde la óptica individual, excluyéndolo de los contextos socio-políticos.

Cuando comenzamos a trabajar desde la habilitación de un espacio de reflexión al inicio de la intervención, se observó resistencia al trabajo grupal. El intercambio con el otro, no era un aspecto valorado por el grupo:

¿Para qué sirve esto?

Yo pienso que estas cosas la podríamos hablar antes, en un bar.

Paralelamente aparecían dificultades para generar una producción conjunta:

Yo leo esto y vos lees esto, y cada una escribe lo que le parece.

Pero ¿todos nos tenemos que poner de acuerdo?, es imposible.

Esta es la "realidad" desde donde hablaban, se veían y vivenciaban estos viejos, identificados (o ¿alienados?) con una realidad construida desde determinados axiomas que generan efectos de verdad.

\section{B - Las condiciones de elaboración de "la vejez"}

Tal como plantea Castoriadis (1997: 3) los sujetos en la medida que seres socializados, son "fragmentos hablantes y caminantes de una sociedad dada". En este sentido, el imaginario social instituido genera un único orden posible. En este ordenamiento se asignan lugares sociales a cada sujeto. Quienes quedan fuera de este orden son inteligidos y aboradados por los de dentro, y en el caso de no adecuarse, deben desaparecer. 
Ustedes que son jóvenes deberían hacer un manual sobre cómo va a ser cuando uno va envejeciendo, hay cosas de las que nadie se libra,

nos dice uno de los miembros del grupo. ¿Qué se está diciendo de la vejez en este enunciado?

Las interpretaciones pueden ser múltiples, pero me quedaré con las condiciones de su elaboración. En este sentido Iacub (2010) planeta que los relatos se construyen en relación a determinadas audiencias, generándose dentro de relaciones sociales, y en cada sociedad se van privilegiar determinadas clases de relatos y relatores. Se constituye así la siguiente operación: Jóvenes + profesionales de la salud mental =manual.

Un sujeto hablado por otro, por un mandato cultural, el cual le asigna significados y sentidos y orienta su deseo.

Uno de los aportes más interesantes del análisis narrativo, es la consideración de la narrativa más que como reflejo de una realidad independiente e individual, como construida socialmente, esto lleva a pensar en las metanarrativas (Villar y Serrat, 2015), aquellas narrativas sociales prevalentes en cierto momento histórico, las cuales moldean, dan lugar y sostienen determinados mecanismos de poder en torno a la vejez (Iacub, 2001). Las mismas, producen efectos concretos sobre las narrativas autobiográficas (Duero y Limón Arce, 2007), generando relatos compartidos (Villar y Serrat, 2015). Ellas representan un aspecto fundamental para entender la identidad personal, en la medida que las características de los relatos condiciona el modo en que las personas construyen su propia identidad en tanto personajes de los mismos.

En esta discusión, haré énfasis en la función performativa del lenguaje, en la que los relatos se elaboran y qué efectos consiguen en el sujeto (Villar y Serrat, 2015). El acento se direcciona entonces, a las condiciones locales que atraviesan la (re)producción e interpretación del relato.

En este sentido, desde el plano de la Post-Gerontología, se propone la ética frente a la contingencia, lo que implica visualizar el caso por caso, el viejo desde contextos de producción específicos, que lo tornan un "tipo de viejo". Esto supone pensar el acontecimiento como construido, fuera de lógicas totalizantes homogenizadoras (Iacub, 2001). 
En esta línea, el discurso institucional, también normativiza y excluye una serie de enunciados referentes a expectativas, roles, y determinados patrones de subjetividad asociados a la vejez, operando como atravesamiento que configura el nivel simbólico e imaginario del sujeto y la dimensión grupal (Fernández y del Cueto, 1985). La institución en la que el grupo está inserto, generada históricamente desde la alineación a elementos conservadores, habilitaría y sostendría la rigidez grupal, limitando las posibilidades de reflexión y crítica. La institución como productora de subjetividad (Kaes, en Markwald, 2003). En su función de apoyatura, el sujeto se sostiene en la institución, habilitando en este caso, un sujeto aprisionado en ella, apegado a la tradición, en detrimento de la emergencia de un sujeto creativo.

Una institución que intente reconstruir una versión ya vivida de la historia, obtura movimientos instituyentes. Se observa cómo la identidad cristalizada que caracteriza al grupo también es la identidad de la institución. En este sentido, como elemento gráfico, llama la atención la estética decorativa del lugar, en la cual predominan cuadros y placas fundacionales, plantas y flores de plástico, un paisaje sin vida congelado en el pasado.

Tal como plantea Fernández y del Cueto (1985) la institución hace al grupo y el grupo hace a la institución. Se observa cómo las dificultades que tiene la institución en el intercambio, la participación, la apertura intergeneracional y hacia la comunidad, son también dificultades del grupo y de los devenires singulares de los sujetos que participan en él:

¿Otra vez hay que trabajar en grupo? Cortito está bien hacerlo, no me quiero quemar la cabeza.

Los gays, los de la caravanita ... cuando yo era joven tenías que ser bien machito. ahora todo es un relajo ... los homosexuales están muy descarados, ahora se puso de moda ser homosexual.

Escuchábamos narraciones de sujetos desde lo que se podría pensar como representaciones subjetivas cristalizadas en torno al proceso de envejecimiento a partir de la asunción de un mandato cultural (e institucional) aceptado como única opción validada socialmente (Iacub, 2010) : 
¿Pero es sobre ahora (vejez) que tenemos que armar un texto?, pero eso sería algo triste..., yo prefiero una anécdota de la infancia.

Yo cuando me miro al espejo digo: ¿quién es esa vieja horrorosa? , me daría tanto palo, por eso detesto que me saquen fotos.

Palabras de angustia y sufrimiento psíquico, resonaban desde sujetos que parecían vivenciar una identidad como desconocida:

Yo cuando recién empecé con mi joroba, cuando me veía en algún reflejo en la calle, no sabía quién era, no me reconocía, ahora ya lo acepté pero no me miro más al espejo,

cristalizándose luego en una identidad bajo el mandato de quien debe ser.

Apreciábamos así el cierre narrativo (Villar y Sarrat, 2015) como resonancia grupal: un compañero habla de su adultez trabajando como subcomisario:

Salía a dar cachiporra a los delincuentes, a los delincuentes hay que pasarlos a degüello.

Relata la "promiscuidad” que existía en las chicas jóvenes de el rancherío8 de Aparicio Saravia9

se angustia mientras relata, se levanta, golpea la mesa y llora.

A nivel institucional, ¿qué lugar hay para la emergencia de la novedad, la cual habilite movimientos instituyentes, desde los cuales se pueda seguir produciendo sentidos, sin experimentar con ello una pérdida identitaria?

Paralelamente, ¿qué capacidad de reformulación del proyecto de vida pensado como una construcción en permanente reformulación, hay en los sujetos que conforman la institución?, ¿qué habilitación hay para la incorporación de lo nuevo y resignificación de lo pasado? Más bien escuchábamos relatos encapsulados desde su potencial singular.

¿Desde dónde digo que escuchábamos eso? O mejor dicho, ¿qué líneas de visibilidad y enunciación permitían la habilitación de esta escucha?

8 Forma coloquial de designar los asentamientos irregulares, tales como favelas en Brasil, villa miseria en Argentina o cantegriles o cantes en Uruguay.

9 Calle de Montevideo la cual atraviesa barrios marginados de la ciudad. 


\section{C - Una herramienta para la provocación de transformaciones}

Aquí toma fuerza la conceptualización de dispositivo como máquina para hacer ver y hacer hablar (Deleuze, 1999) ¿Es el sujeto la resultante del cruce entre los múltiples procesos de subjetivación que tienen lugar a partir de captura desde múltiples dispositivos?

¿Desde qué dispositivos había sido capturada esta vejez? Quizá pensar en ellos nos permite inteligir desde donde fue definida y desde donde se veían y hablaban estos sujetos.

De acuerdo a la noción de dispositivo, desde su carácter estratégico (Foucault, 1985) podríamos interrogarnos, sobre qué líneas de subjetivación hacen posible los dispositivos dispuestos en torno a la vejez.

Si pensamos al dispositivo como forma política para dar soluciones pragmáticas de orden práctico y ético-político, enmarcado en una función estratégica dominante (Foucault, en Heredia, 2012) el mismo está imbricado con la noción de sujeto desde la que trabajamos, las representaciones sociales que nos atraviesan y a las que adscribimos, un determinado modelo de salud-enfermedad desde el cual intervenimos, en suma, a la ideología que mueve nuestro accionar.

En nuestra intervención, resonaba e iba tomando cuerpo el planteo de la Gerontología Crítica, el cual propone la praxis como acción posibilitadora de un camino emancipatorio (Iacub, 2001).

Es así como se buscó conformar un dispositivo que habilitara la reflexión sobre los diversos contextos (o dispositivos) en los cuales estos viejos estaban objetivados (Iacub, 2001). Un dispositivo pensado como herramienta para la provocación de transformaciones (Jean Francois Lyotard en Anne-Marie Duguet, 1996).

A medida que transcurrían los encuentros, a partir de la escucha de sus relatos, los sujetos comenzaron a identificarse, apropiándose del espacio grupal (Vallejo Jiménez, 2006). Comenzamos a visualizar la apertura colectiva hacia un posicionamiento crítico del proceso de envejecimiento, en diversos órdenes:

Te das cuenta que tenés una edad cuando el guarda del ómnibus pide a gritos 'un asiento para la abuela', no me gusta que me llame abuela alguien que no conozco, yo no soy tu abuela y tampoco soy abuela.

El intento de deshacerse de los viejos, de mandonearlos, de manejarles la vida. 
Comienzan a aparecer elementos que plantean la vejez como devenir singular a lo largo del curso de vida (Zarebski, 2016). Es así como por ejemplo empiezan a debatir sobre sus propias relaciones afectivas, atravesadas por el rol de género de una época:

Los amigos vienen y van, pero tampoco fui de tener muchos amigos... no cultivé muchas amistades debido a que le di prioridad a mi marido y a mis hijos.

Aparecen cuestionamientos a la institución, por ejemplo, ante la negativa de la misma para llevar alimentos para compartir, o la dificultad de captar nuevos socios, pensada desde la poca difusión de actividades a nivel barrial o la no convocatoria a asambleas colectivas.

Muestran su molestia en relación a la dominación desde el saber médico y las imposiciones a nivel familiar, y en este sentido como la percepción del cuerpo aparece desde la mirada del otro, desde la vivencia de un cuerpo enfermo:

Me tienen hasta acá con el cigarro, antes fumábamos sin problemas, todos lo hacíamos. Me tienen atosigada, lo que hay que hacer lo dicen los hijos.

Yo antes no estaba pendiente del cuerpo, ahora sí, te dicen que comas, que no comas.

Podemos pensar entonces que la metodología de trabajo grupal habilitó la visualización y análisis de representaciones imaginarias comunes como disparadores del imaginario grupal (Fernández y del Cueto, 1985), ofreciendo un espacio para la escucha y resignificación de la historia singular generadora de la producción de efectos singulares y novedosos.

Sin embargo, si consideramos el carácter del dispositivo como esencialmente estratégico, inscripto en un juego de poder y saber, el cual el mismo genera y condiciona, supone cuestionarnos sobre la intervención y la comprensión de las prácticas, en tanto generadoras de efectos discursivos que provocan modos de subjetivación. Perfomativamente hablando (Phoenix, Smith \& Sparkes, en Villar \& Serrat, 2015), el discurso mismo es intervención.

Entonces, la apertura reflexiva visibilizada, ¿no podría estar intercedida por el propio dispositivo, en la medida que máquinas de visibilidad y enunciación? Reconocer que el dispositivo habilita y normativiza ciertos discursos, no invalida considerar que a partir de 
las características del grupo y los flujos de ruptura en relación a la institución en la cual está inserto, la apertura reflexiva significó un movimiento instituyente desde lo micro.

\section{D - Una herramienta para hacer ver y oír, lo invisibilizado y acallado}

Así como la metodología de trabajo grupal encontró resistencias, la incorporación de técnicas artísticas en el dispositivo de intervención, obtuvo una buena recepción desde el inicio del proceso, facilitando la apertura reflexiva y la toma de conciencia a través de la posibilidad de apertura hacia una postura crítica ante el mandato social sobre la vejez; así una participante plantea:

Me sentí identificada (con el personaje de una película proyectada) porque a veces no puedo hacer algunas cosas según mi gusto o mis necesidades, porque familiares cercanos quieren imponer su manera de pensar.

Otras compañeras discuten acerca de sus experiencias de viudez e identificándose con el rol establecido para la mujer signado por los cuidados a la familia, la subordinación al hombre-marido y la postergación del deseo personal, reflexionan:

La actriz principal despierta de un duelo, lentamente se reintegra a la vida y comienza a hacer todo lo que siempre quiso y postergó por la atención a la vida hogareña, liberada de una vida pendiente a los demás, se da cuenta que puede disfrutar con lo que realmente desea.

Por primera vez escuchábamos hablar sobre el deseo. Salimos del plano organicista para introducirnos en los hilos deseantes que también atraviesan la constitución grupal (Fernández y del Cueto, 1985).

Reflexionaré sobre la mediación artística, como herramienta- dispositivo, colocando el acento en lo que la experiencia artística posibilita10.

Pienso el arte como herramienta más que como fin, más en el proceso que en

10 En éste trabajo no abordaré la reflexión sobre los mediadores artísticos específicos que se utilizaron en la intervención (cine foro y literatura) y en las interesantes condiciones de posibilidad que cada uno de ellos genera. 
producto. En este sentido me alejo de su finalidad estética encerrada muchas veces en galerías al alcance de algunos pocos, en salas llenas donde se oye o ve, lo que se pretende sea enunciado o visto. La repetición constante de lo idéntico. La reproducción de un orden.

¿Es deseable para este orden ver u oír aquello que no vende, cuestiona y quiebra? Y en este contexto, ¿qué pasa con la vejez?

La experiencia artística adquiere de este modo una significación política, en la medida que habilita estrategias de resistencia mediante la construcción de dispositivos alternativos que puedan oficiar como herramientas de criticidad en relación a los procesos de subjetivación. Construcción de máquinas, al decir de Deleuze (1999), para hacer ver y oír, en éste caso, aquello invisibilizado y acallado, como es el caso del deseo en la vejez.

¿Es el arte una herramienta de posibilidad creadora que habilita las rupturas del ordenamiento hegemónico?

Si pensamos en cierto ordenamiento, pensamos desde la contingencia que implica un contexto de producción particular de sentidos, aquellos que vuelven al viejo, como vimos anteriormente como enfermo, dependiente y asexual:

Influyen los tristes límites que las familias imponen, sin darse cuenta de la intimidad que necesitan las parejas mayores y peor cuando son los residenciales, que desconocen la sexualidad en la ancianidad.

La creación artística como herramienta de ruptura, ¿puede ser separada de un contexto histórico social y político? Rolnik (en Bugnone, 2014), señala que existe una tensión entre la organización dominante y el plano de lo “sensible, invisible e indecible”. El arte puede así instituir nuevas divisiones de lo sensible, en la medida que propone y posibilita una reconfiguración de las formas habituales de representación, esto es lo que le permite redibujar un paisaje naturalizado, establecido como el real paisaje por cierto orden. Aparece entonces la posibilidad de intervención desde la mediación artística como modo de oponerse a modelos hegemónicos en la vejez, herramienta que habilita nuevas producciones de subjetividad y narrativas alternativas.

Por último, destaco que merece una discusión aparte, el riesgo de utilitarismo que comporta el uso del arte como herramienta, en tanto sea capturado al servicio de lógicas opresoras. Solo aventuro decir, que considero que su aspecto liberador se haya en la 
posibilidad de la creación del acontecimiento singular. Como plantea Bugnone (2014) su capacidad no reproductiva para crear la experiencia, ajena a los sentidos disponibles y por ello conflictual.

\section{E - El camino de lo singular y lo colectivo}

Si bien el grupo adquiría ciertos posicionamientos críticos en torno a representaciones hegemónicas sobre la vejez, comenzamos a visualizar una dialéctica constante de apertura reflexiva, seguida por la reaparición de elementos conservadores. Así por ejemplo, ante una propuesta de trabajo en torno a la escritora Simone De Beavouir, comienzan cuestionando las elecciones sexuales de la misma, a partir de adjetivos como “chanchita”. Sin embargo, otros responden absteniéndose a realizar juicios de valor:

Nadie puede tirar la primera piedra.

Se comienza a observar una apertura reflexiva en diversas áreas. Es así como por ejemplo, valoran el papel de la intelectualidad y la incidencia del contexto históricopolítico:

Eran grandes pensadores como los griegos, tenían otras maneras de interpretar la filosofía y la vida.

Reflexionan acerca de cambios que proponen como "positivos" a nivel de género en la actualidad, en relación a formas de ser mujer y como la misma opera a nivel de los cuidados:

Ahora se ven hombres jóvenes con niños en el ómnibus, los cuidan con una ternura...los peinan.

Luego el grupo regresa a representaciones cristalizadas y conservadoras:

El problema es a nivel social, en un cante los tipos son atorrantes11, terrajas12 y las chiquilinas de 14 solo tienen hijos, viven de los aportes públicos, si gobernaran bien... pero no hay planes ni manos que aprieten.

11 Forma coloquial y despectiva de referirse a una persona mediocre, la cuales se asocian con un alejamiento del mundo del trabajo por cuestiones de comodidad.

12 Forma coloquial y despectiva de referirse a una persona con mal gusto o vulgar. 
El grupo permaneció apegado, luego de la intervención, a representaciones vinculadas a lo orgánico y el declive. Sin embargo, al final del proceso se logró la visualización de la vejez como devenir singular a lo largo del curso de vida, apareciendo elementos de historicidad y devenir, y la visualización de la vejez como construida singularmente.

Vuelvo a preguntarme, en sus aspectos repetitivos y aspectos transformadores (Fernández y del Cueto, 1985) ¿no es el atravesamiento institucional el ahora actualizado e ilustrado por el grupo, en el repliegue a lógicas conservadoras, luego de la apertura reflexiva?. Sin embargo, ¿puede el grupo sostener una transformación total de las representaciones sobre la vejez en tanto desprenderse de las mismas generaría la pérdida de referencias identitarias, sostenidas desde las metanarrativas a nivel social e institucional?

Considero que a partir del entrecruzamiento del dispositivo grupal con el aporte de la mediación artística, los sujetos accedieron a espacios de reflexión, adquiriendo ciertos posicionamientos críticos, en torno a representaciones hegemónicas sobre la vejez, los cuales dentro de la lógica institucional en la cual están inscriptos, se configuran como lógicas contrainstitucionales, y dentro del orden social donde transcurren sus vidas como movimientos contra hegemónicos. 


\section{Capítulo 7: Consideraciones finales.}

Rita, nos acompañaba desde el 2015 en los talleres de estimulación cognitiva. Nunca nos dio un beso como saludo, lo negaba alegando el temor a contagiarse de enfermedades virales a partir de haber sufrido tuberculosis a los nueve años, según dice a raíz del contacto con otro contagiado. Solo parece tener cerca a la iglesia y a Dios. El grupo respeta su posición, a nadie parece llamarle la atención su postura. En la institución Rita se siente cómoda, comúnmente uno pasa por la secretaria para ingresar al salón del taller y es una excepción cuando cansadamente la secretaría levanta la cabeza para esbozar un hola entre una sonrisa caricaturesca.

Rita un día se cuestiona acerca de qué movimientos genera para acercarse a otros y qué barreras interpone para que otros se acerquen a ella, se angustia y al final del encuentro sus compañeros la abrazan y Rita se deja abrazar. Al tiempo Rita saluda alegremente con un beso, cuando va y cuando viene, añadiendo:

Ésto ya lo cambié.

¿Qué posibilitó este cambié ?

En primer término me cuestiono sobre el dispositivo de intervención, ¿cómo poder sostener que el cambio se debió al mismo? Quizá en parte, en tanto habilitación de posibilidades de elaboración de sentidos colectivos, de espacio para la producción de alteridades.

Según Deleuze (en Martínez, 2006: 513) la tarea de producción de sentido13 es una tarea ética y ella "no está en el hombre ni en Dios (...) no es nunca principio ni origen sino producto”, de este modo el dispositivo no generaría un descubrimiento del sentido (lo que implicaría que ya esté pre construido), ni una restauración (lo que apelaría a la

13 "El sentido es concebido por el autor como una entidad incorpórea que porta la posibilidad de ser expresado o expresable, enunciado o enunciable por el lenguaje a través de proposiciones. Pero no en todas las relaciones que se dan en una proposición hay emergencia del sentido. El sentido configura una de las dimensiones de la proposición, cuyo rasgo fundamental es la implicación con el acontecer presente, con lo que pasa, con lo que es en el instante” (Ripamonti s/f :2). 
reconstrucción de un original), ni por reemplazo (lo que aludiría a la sustitución de un original). El mismo parte del deseo como flujo creador de sentidos configurándose como línea de fuga colectivas frente a un orden dominante.

Rita ya no se siente cómoda, su historia de vida tal como venía siendo narrada, comienza a presentar fisuras. En esta línea, ¿podemos pensar el cierre narrativo desde el plano de lo individual como un momento que quebranta la lógica personal, y desde lo grupal como un momento que quebranta en la adaptación a un instituido social?.

Pensarlo desde este plano, implicaría su consideración como portavoz o síntoma. En este sentido, supone la despatologización del mismo, en su acción posiblitadora. Ahora bien, el devenir de su afán posibilitador, estaría condicionado por el dispositivo desde el que se aborde al sujeto, el cual daría paso a su expresión creadora como un movimiento de generación de nuevos sentidos, un instituyente disfuncional a las relaciones de poder imperantes, o a su captura14.

Entonces, ¿el tamaño de cómo nos vemos es el tamaño de nuestra estatura? Quizá la reflexión debería rondar en qué tipo de prácticas y discursos sostenemos y promovemos, los cuales se configuran como condiciones que posibilitan al sujeto ver como como se ve, en tanto expropiación o apropiación de la vida, como construcción singular y colectiva en permanente transformación. En definitiva, una reflexión sobre la creación de condiciones de libertad.

14 Imagino frases como: es porque es viejo, es porque está solo, es porque está demenciado, es porque está deprimido. 


\section{Referencias bibliográficas}

BANCHERO, Serrana; ROVIRA, Adriana. Incidencia de un dispositivo clínico de mediación artística con un grupo psicoterapéutico de adultos mayores. IX Jornadas de Psicología Universitaria. Memoria y Transformación Social: el conocimiento en la frontera, Montevideo, 2013. Recuperado el 14 de Junio de 2018, de: https://mediacionartistica.files.wordpress.com/2013/05/ma.pdf

BERRIEL, Fernando. Imagen del cuerpo, modelos y emblemas identificatorios en los adultos mayores. Tesis de Maestría. Facultad de Psicología de la Universidad Nacional de Mar del Plata, 2003.

BERRIEL, Fernando; PAREDES, Mariana; PÉREZ Robert. Sedimentos y transformaciones en la construcción psicosocial de la vejez. In.: Proyecto Genero y Generaciones: reproducción biológica y social de la población uruguaya, pp. 20-109, 2006.

BREA, José L. Nuevos dispositivos del arte. Transformaciones de las prácticas artísticas en la era del capitalismo cultural electrónico. In.: Telos: Cuadernos de Comunicación, Tecnología y Sociedad, (56), pp. 93-102, 2003.

BUGNONE, Ana. Algunos conceptos para pensar la política y lo político en el arte. Primeras Jornadas de Estudios Políticos Latinoamericanos, 5 al 6 de junio de 2014. In.: Memoria Académica. La Plata, Argentina. Recuperado de: http://www.memoria.fahce.unlp.edu.ar/trab_eventos/ev.3935/ev.3935.pdf

BUSTOS SÁNCHEZ, Alfonso. Escritura colaborativa en línea. Un estudio preliminar orientado al análisis del proceso de co-autoría. In.: RIED. Revista Iberoamericana de Educación a Distancia [en línea], 2009: Recuperado en: http://www.redalyc.org/articulo.oa? id=331427211004

CABRERA DÍAZ, Cristina. La vejez a proscenio: proyecto de sistematización de la práctica con adultos mayores y teatro en el hogar israelita. Pre-proyecto de investigación , Universidad de la República (Uruguay). Facultad de Psicología, 2015. Recuperado en: https://www.colibri.udelar.edu.uy/jspui/handle/123456789/7941?mode=full

CASTORIADIS, Cornelius. La institución imaginaria de la sociedad. Barcelona: Tusquets Editores, 1975.

El imaginario social instituyente. In.: Zona erógena, 35, pp. 1-9, 1997.

DELEUZE, Gilles. ¿Qué es un dispositivo?. In.: Michel Foucault, filósofo, Editorial Gedisa, 1999. 
DUERO, Dante G..; LIMÓN ARCE, Gilberto. Relato autobiográfico e identidad personal: un modelo de análisis narrativo. In.: Revista de Antropología Iberoamericana, mayoagosto, año/vol. 2, número 002, pp. 232-275, Madrid, España, 2007.

DUGUET, Anne-Marie. Actualité du virtuel Actualizing the Virtual. París, Ed. Centre Georges Pompidou, 1996. Recuperado en: https://www.bibliothequesclermontmetropole.eu/s/search.php?action=Record\&id=clerco_CET754761

FOUCAULT, Michel. Saber y Verdad. Madrid: La Piqueta, 1985.

GUERRERO, Catalina; MARTÍNEZ ESQUEMBRE, María Z. Resultados de un programa de educación a través del arte dirigido a personas mayores. In.: Quaderns d' Animmació i Eduació Social; no 25, Universidad de Murcia, 2017.

HEREDIA, Juan M. Dispositivos y/o Agenciamientos. In.: Contrastes, revista Internacional de Filosofía, 19(1), 2012.

HERNÁNDEZ SAMPIERI, Roberto; FERNÁNDEZ COLLADO, Carlos; BAPTISTO LUCIO, María del Pilar. Metodología de la investigación. México: McGraw-Hill Interamericana, 2004.

IACUB, Ricardo. La Post-Gerontología. Hacia un renovado estudio de la Gerontología. In.: IV Congreso Chileno de Antropología. Colegio de Antropólogos de Chile A. G, Santiago de Chile, (2001)

El Envejecimiento desde la identidad narrativa. In.: VERTEX Rev. Arg. de Psiquiat. 2010, Vol. XXI, pp. 298- 305, 2010.

Identidad y Envejecimiento. Buenos Aires, Argentina: Paidós, 2011.

KEHL, Susana; FERNÁNDEZ, José M. La construcción social de la vejez. In.: Cuadernos de Trabajo Social, No 14, pp. 125-161, .2001.

LAURETTI, Paola; GONZÁLEZ, Lesbia; FLORES, Yudelkis. Cine interactivo como estrategia de intervención grupal. In.: Revista Venezolana de Información, Tecnología y Conocimiento, Vol.6 , pp 57-59, 2009.

MARKWALD, Diana. Sujeto, grupo,institución. ¿Una relación posible?. In.: Campo Grupal, N. ${ }^{\circ}$ 47, pp. 4-6, 2003.

MARTíNEZ, Miguel A. La filosofía de Gilles Deleuze: del empirismo trascendental al constructivismo pragmático. Tesis de dutoramento. Facultad de Filosofía. Universidad Santiago de Compostela, pp. 513, 2006.

MORENO GONZÁLEZ, Ascensión. La mediación artística: un modelo de educación artística para la intervención social a través del arte. Facultad de Bellas Artes, 
Universidad de Barcelona, España: Revista Iberoamericana de Educación ISSN: 16815653, 2010.

PÉREZ DÍAZ, Julio. La demografía y el envejecimiento de las poblaciones. In.: Staab, A. S.; Hodges, L.C. Enfermería Gerontológica. México D.F., 1998.

PÉREZ FERNÁNDEZ, Robert. La construcción subjetiva de la Realidad. Psicología, Neurociencias, políticas e imaginario social. In.: Conferencia Inaugural de actividades académicas. Universidad de la República. Facultad de Psicología, 2009.

PESSOA, Fernando. Poesías completas de Alberto Caeiro. España: Pre-Textos, 1997.

QUINTANAR, Fernando; GARCÍA, Carlota J. Perfil de representaciones de la vejez mediante un test proyectivo de frases incompletas (FIIRAV-I) Profile of representations of aging using an incomplete sentences projective test (FIIRAV-I). In.: Psicología y Salud, Vol. 23, Núm. 1: 33-43, 2013.

RIPAMONTI, Paula C. En torno al sentido, un ejercicio reflexivo desde Deleuze. In.: Question, 1. Universidad Nacional de Cuyo, Argentina, 2009.

SALVAREZZA, Leopoldo. Psicogeriatría. Teoría y clínica. Buenos Aires: Paidós, 1988.

THEVENET, Nicolás. Cuidados en personas adultas mayores: análisis descriptivo de los datos del censo 2011. Mides, 2013.

VALLEJO, Felipe. Espacio grupal para pacientes psicóticos en un Centro de Salud Mental. En: Apuntes de Psicología, vol. 24, pp 331-343, 2006.

VILLAR, Feliciano; SERRAT, Rodrigo. El envejecimiento como relato: Una invitación a la gerontología narrativa. In.: Revista Kairós Gerontologia,18 (2), pp. 09-29. São Paulo, Brasil, 2015.

YUNI, José A. Integraciones metateóricas en el paradigma del curso de la vida. Encuentro Grupo Editor, 2011.

ZAREBSKI, Graciela. La Teoría del Curso de la Vida y la Psicogerontología actual: frutos simultáneos de un mismo árbol. In.: Yuni, J. (comp.) La vejez en el curso de la vida. Córdoba: Encuentro Grupo Editor, 2011.

Recebido 23/04/2019

Aprovado 28/05/2019 